\title{
Personal income inequality in USA from a two-class perspective: $2004-2018$
}

\author{
Rishabh Kumar* \\ University of Massachusetts Boston
}

*Email: Rishabh.Kumar@umb.edu.

This article was written for Tom Michl's festschrift session at the 2021 meeting of the Eastern Economics Association. I am grateful to all participants of this session, Simon Mohun and Rudi Von Arnim for their feedback and an anonymous referee for their useful comments and suggestions 


\begin{abstract}
US incomes follow a two class pattern - an insight originally shown by physicists in the econophysics literature. The upper class fits a power-law, or Pareto distribution, while the lower class follows an exponential distribution. Growing income inequality is explained by rising between-class inequality over the 2004-2018 period. The upper class has two important features which I analyze: it has expanded in size, accounting for the top 6 percent of the income distribution in 2018, and it is more complex than just capitalists because the labor income distribution also follows a two-class structure. This shows that homoploutia - individuals rich in both labor and capital income - is a defining characteristic of the upper class under modern capitalism. I argue that despite what appear as blurred lines from a traditional sense, income inequality and its rise in the US is very much a class based phenomena.
\end{abstract}

Keywords: Income Inequality, Pareto Distribution, Power Law, Gini Coefficient, Exponential Distribution, Homoploutia. 


\section{Introduction}

One of best known stylized facts about income distribution is the presence of power laws in societies where there are no upper limits to income. That is, the population with income greater than some cutoff $y$ is proportional to $y^{-a}$. This formula allows for the presence of a non-trivial fraction of society with extraordinarily large incomes relative to the social mean, or median. For example, the average income of the top percentile in the US is nearly twenty times ${ }^{1}$ per adult national income.

Originally, Pareto (1896) applied a power law to data from nineteenth century European tax returns and land ownership records. Pareto was interested in advocating the idea that elites are universal and present in all sorts of societies. However, this finding is incomplete; modern data shows that power laws cannot be generalized to all of society. In a series of papers, Victor Yakovenko and his coauthors $^{2}$ showed that the top 1-3 percent of the income distribution does indeed fit a power law, but the vast majority fits an exponential formula; the number of people with incomes greater than $y$ are proportional to $e^{-y}$. Thus, the probability of larger and larger incomes decays at an exponential rate. This finding is important; Tao et al. (2019) showed that the exponential distribution fits the middle class of income distributions in a sample of 67 countries with varying levels of per-capita income. Thus, while Pareto's argument about omnipresent elites seems important, there are also regularities in statistical laws that apply to the rest of the income distribution. This is a powerful metaphor to partition society into an

\footnotetext{
${ }^{1}$ This statistic was taken from the World Inequality Database for the year 2014

${ }^{2}$ See Drăgulescu and Yakovenko (2001) and Silva and Yakovenko (2004)
} 
upper and lower class purely ${ }^{3}$ on the basis of a discontinuity in the probability distribution.

In this chapter, I extend the analysis of two-class structure of incomes to US data for the 2004-2018 period. I confirm distinct statistical laws apply to the vast majority and the top of the income distribution. The upper class fits a powerlaw (Pareto) formula with parameters that vary in time, and income shares that correlate to asset price inflation. The lower class follows an exponential law and mean income within this class are stable in time, controlling for inflation. Rising income inequality in America, measured using the Gini coefficient, is predominantly driven by between class inequality. This stands in contrast to within upper class fluctuations driving the Gini during the late twentieth century (Mohun, 2016; Schneider and Tavani, 2016). An important reason for between-class inequality in recent decades is the encroachment of the power-law on a larger share of the population (6 percent in 2018). Absorption of the richest members of the lower class into the upper class contributes to higher inequality in aggregate, and on the margins of both classes.

While power laws are not exotic to economists - Gabaix (2016) wrote an influential survey on their applications - government statisticians and economists primarily use the Pareto distribution to estimate income shares for fixed fractions (top 1 percent, top 5 percent etc) using fiscal data (Atkinson and Piketty, 2010). My approach is parsimonious: take the point where the power law actually applies

\footnotetext{
${ }^{3}$ Usually, class distinctions in the income distribution rely on intrinsic characteristics of individuals. For example, education and skills (Autor, 2014), selecting a fixed fraction like the top 1 percent (Piketty and Saez, 2003), or source of income (Shaikh, 2017)
} 
as a dynamic threshold of where to start counting individuals as upper class. This approach also applies to labor income, where I show that the two-class structure exists as well. Accordingly, my analysis accounts for a distinct trend in modern capitalism: an overlap between those rich in labor and capital income. This feature distinguishes present day capitalism from the classic capitalism of the past where the rich were capital income earners only (Milanovic, 2019). The gist of this research is that while the upper class is made up of a complex strata of capitalists, supermanagers, superstars and highly paid professionals, the fact is that growing inequality in the US is very much a class based phenomenon.

\section{Signatures of Exponential and Pareto distributions}

For simplicity, and to restrict the scope of analysis to income distributions, I will define the exponential and power law formulas in terms of cumulative probabilities $^{4}$ or survival functions - that is, the proportion of population with income larger than $y$, expressed as a function of $y$. The exponential distribution is defined for $0<y<\infty$ in terms of cumulative probability $C(Y>y) \propto e^{-y / T}$. Here, $T$ is both the mean and standard deviation of the distribution. Basically, higher mean incomes also imply higher interpersonal inequality. The logarithm of $C(Y>y)$ translates to $\log (C) \propto-y / T$, which is to say that $\log$ probabilities are linear in $y$. Thus, empirical data plotted on a vertical log scale should collapse on a downward sloping straight line, whose slope is given by $-1 / T$.

\footnotetext{
${ }^{4}$ See Drăgulescu and Yakovenko (2001) for detailed mathematical exposition of exponential and power law distributions
} 
The Pareto (or power law) distribution has cumulative probabilities given by $C(Y>y) \propto y^{-a}$, or $C(y)=\left(\frac{y}{k}\right)^{-a}$. Here, $k>0$ is a scaling parameter which is usually interpreted to be the minimum income at which the Pareto distribution applies and $a$ is the Pareto coefficient. The fatness of the tail is inversely proportional to $a$ so that for two societies, the one with lower $a$ will have more extremes in the upper tail of the income distribution and display the potential ${ }^{5}$ for erratic behavior. While the mean of the distribution is important in the exponential law, it is less informative in a Pareto distribution. If $a$ takes values below 1, then the mean, calculated as $\frac{a k}{a-1}$, is not defined and for $a<2$, the variance is not defined. I will rely on visual signatures to identify a Pareto in empirical data. On a log-log scale, cumulative probability for a Pareto distribution collapses on a downward sloping line since $\log (C) \propto-a \log (y)$ and the slope $(-a)$ can be estimated via simple OLS.

The difference between an exponential and Pareto are shown on a log-log scale in Figure 1 for $y \in(1,100)$ and $k=1, T=1$. Visually, cumulative probabilities for exponential distributions decay rapidly (in a hump shape on log-log scale) for large values of $y$, making extreme observations nearly impossible.

\footnotetext{
${ }^{5}$ Consider an illustrative case where ten individuals constitute a society and the income of nine of ten is in the range of $\$ 50,000-100,000$. Now, adding a tenth member with an income of $\$ 10$ million makes the mean totally unrepresentative of incomes which are more frequently observed
} 


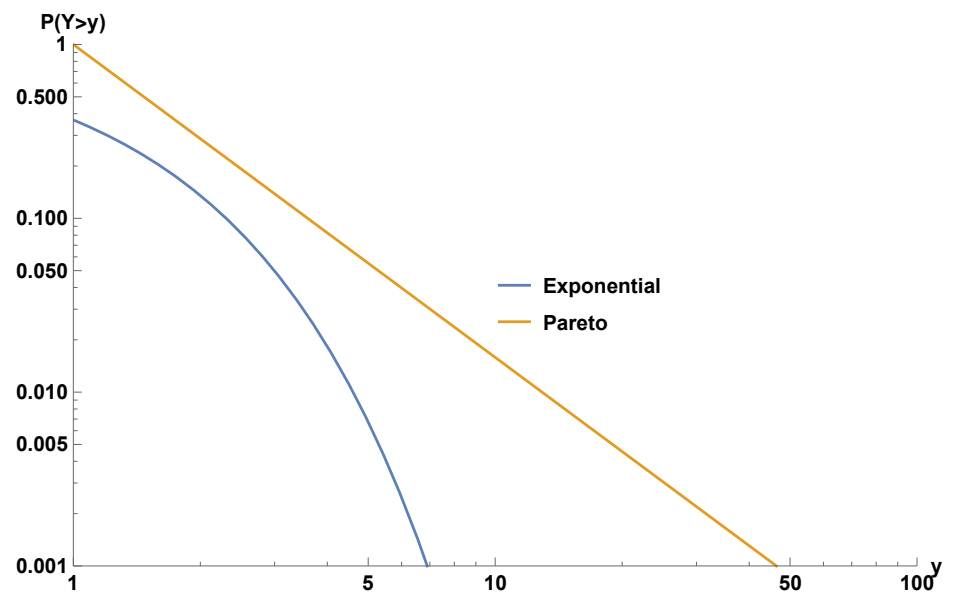

Figure 1: Cumulative probabilities $P(Y>y)$ on log-log scale for Exponential and Pareto distribution for $y \in(1,100)$. Pareto coefficient $a=1.8$

To test these distributions empirically, I collected publicly available raw data ${ }^{6}$ from the website of the Internal Revenue Service (IRS) for the years 2004-2018. These data are tabulated in the form of total income tax returns filed and total income as a function of different income brackets, or intervals. These raw tables can be cumulated and converted into cumulative returns above each income threshold (the lower interval of each bracket) - i.e in a format that gives the cumulative probability of income above any cutoff. For my main analysis, I use Annual Gross Income (AGI) as the benchmark income concept. I have also separately utilized returns pertaining exclusively to the distribution to wages and salaries. The population unit, as per these data, is the total number of tax units i.e individuals

\footnotetext{
${ }^{6}$ The relevant tables are All Returns: Sources of Income, Adjustments Deductions and Exemptions, and Tax Items published as Individual Complete Report (Publication 1304), Table 1.4. The IRS Tax Stats website is: https://www.irs.gov/statistics/soi-tax-stats-individual-statisticaltables-by-size-of-adjusted-gross-income
} 
or married couples filing tax returns. The control total for income is obtained by cumulating total fiscal income (AGI) filed by all tax units for each year.

\section{Two class structure of US incomes: 2004-2018}

I present results, starting with the lower class. Figure 2 considers the distribution of income for (roughly) the bottom 90 percent of the population. The upper panel plots cumulative probabilities against nominal income thresholds; the data appear as downward sloping lines on a vertical log scale (log probabilities), as predicted by the exponential formula: $\log C \propto-y$. The slopes show variation in time, getting flatter on account of rising mean incomes ( $1 / T$ declines) in nominal terms. Basically, people's incomes go up over time due to inflation so that the fraction that makes more than a fixed cutoff (say, $\$ 100 \mathrm{~K}$ ) will be larger every few years. For example, in 2004, around 10 percent of the lower class had incomes greater than USD 100K, but in 2018, the corresponding fraction was around 20 percent. To adjust for increasing mean incomes, I rescaled the data by normalizing the cutoff by mean income for each year. Following this rescaling, the data for 20042018 collapse on one solid line (lower panel) whose slope is taken from 2004 data alone. Therefore, the exponential formula is a good predictor ${ }^{7}$ of cumulative probabilities for the lower class and this distribution is stable in time for meanadjusted cutoffs $y / T$. Or, put simply, the vast majority is in equilibrium inequality.

\footnotetext{
${ }^{7}$ In a discussion about the two class income distribution model, Schneider (2015) argues that adding a log-normal distribution can improve the fit. The main advantage of sticking with an exponential is simplicity because it can be expressed using a single parameter.
} 


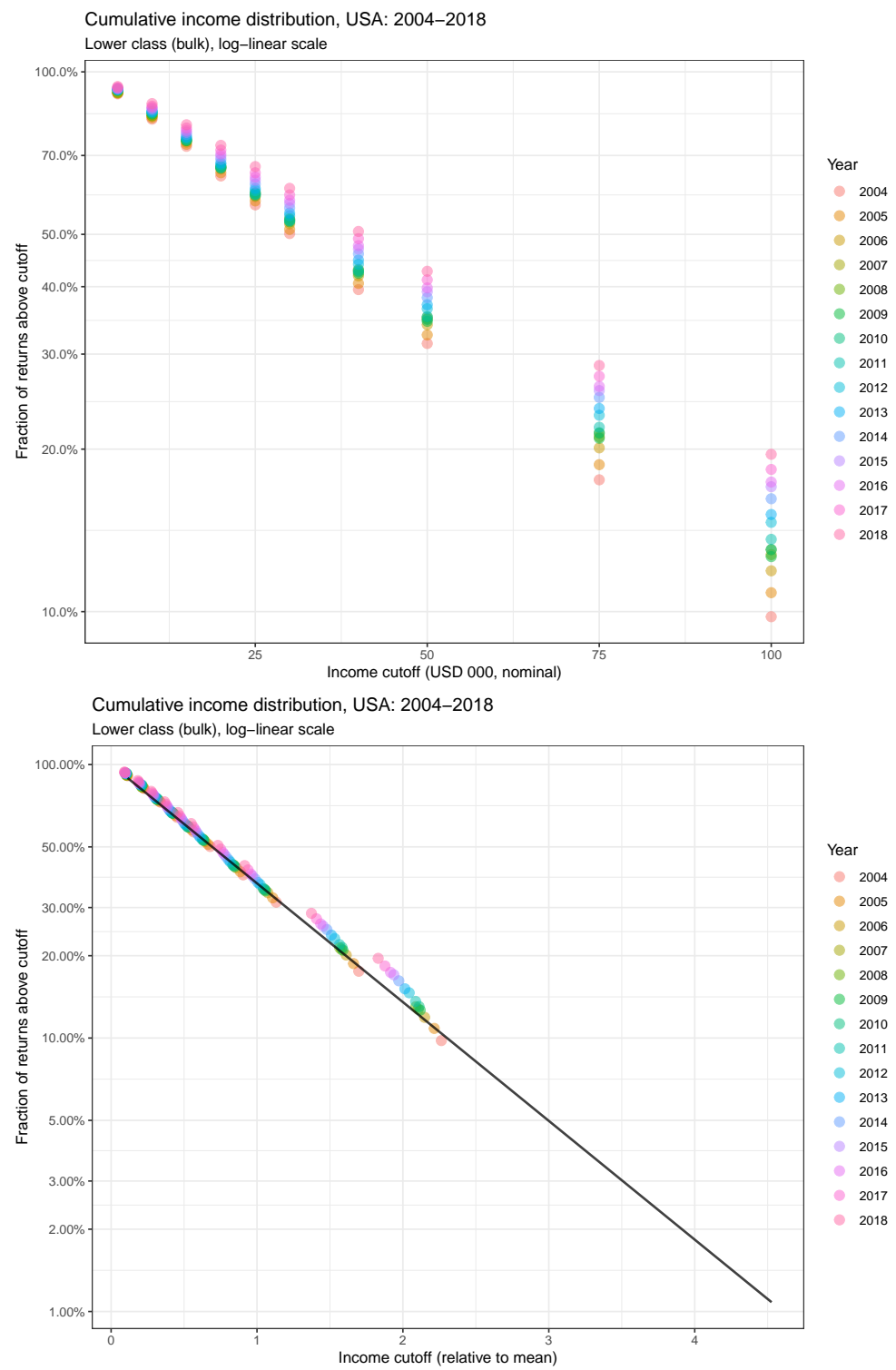

Figure 2: Lower class in exponential decay. Log-linear scale

The upper range of income data $(y>4 T)$ is plotted on a log-log scale in Figure 3 (upper panel). Probabilities collapse on a straight line thus confirming a powerlaw rule (Pareto) for the rich, in line with $\log C \propto-a \log (y / T)$. However, the 

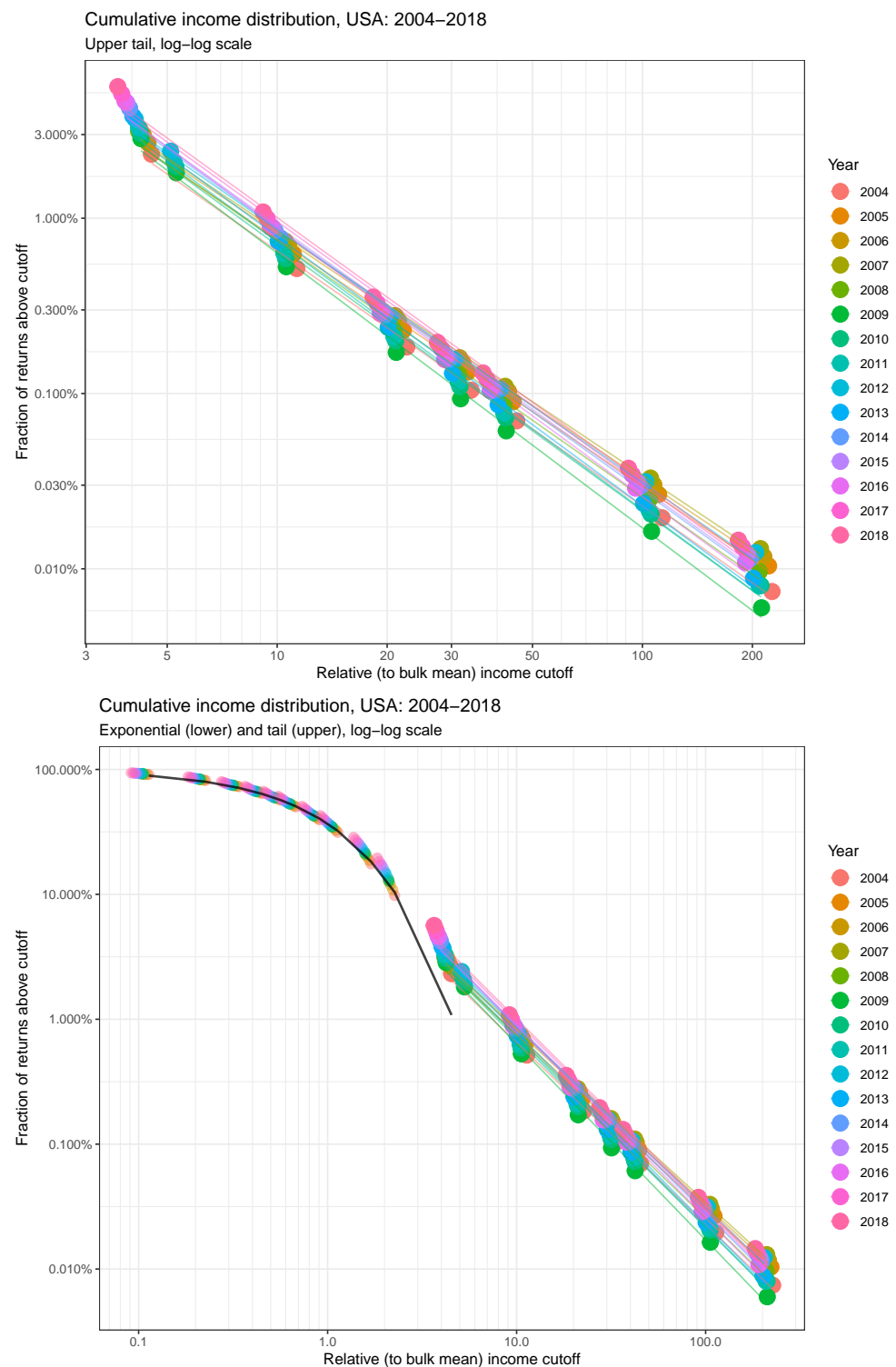

Figure 3: Upper tail shown in upper panel. Both classes combined in lower panel. Both figures are on a log-log scale

upper tail is not stationary and in fact the parameters of the power-law deviate substantially over time. Thus, while the lower class was found to be in equilib- 
rium inequality, the same is not true for the rich. To visualize the full extent of the data, I plotted the entire range of income on a log-log scale in the lower panel of Figure 3. Because the lower and upper class follow different probability distributions, the rate of decay of cumulative probability is discontinuous on $y / T$. For the lower class, decay is hump shaped (exponential), or rapid, while it is linear (power law), thus slower, for the upper class agreeing with the respective rates of decay proposed in Figure 1.

These differential rates of decay drive home the main novelty of the two-class model; the exponential distribution fits the vast majority (lower class) but its predicted probabilities $C(Y>y)$ diverge from actual data as $y$ increases beyond 3-4 $T$ because the upper class follows a more extreme income distribution law. Even though the population in the power-law upper tail is small (3-6 percent), it accounts for a very large fraction of income - the area under the probability curve is large due to linear decay on a log-log scale. Information about the distribution of income for the vast majority thus tells us little about actual income inequality because large events (super high incomes) happen mostly on the other side of the social partition, i.e. the upper tail. The magnitude of incomes in the upper class also imply that instability in the power-law parameters disproportionately impacts aggregate income inequality (remember, the lower class is stable in $T$ ). Figure 3 agrees with the original findings of Silva and Yakovenko (2004) thus confirming the two-class model as a statistical regularity over 1983-2018. The importance of granular coverage of the upper tail cannot be overstated. With top-coded data, tabulations up to 3 or $4 T$ would cover most of the population (more than 90 percent), but miss most of the skewness. For example, the exponential predicts that 
less than 0.1 percent of the population has income larger than $10 T$, whereas in fact the actual population above this threshold is almost 4-5 percent.

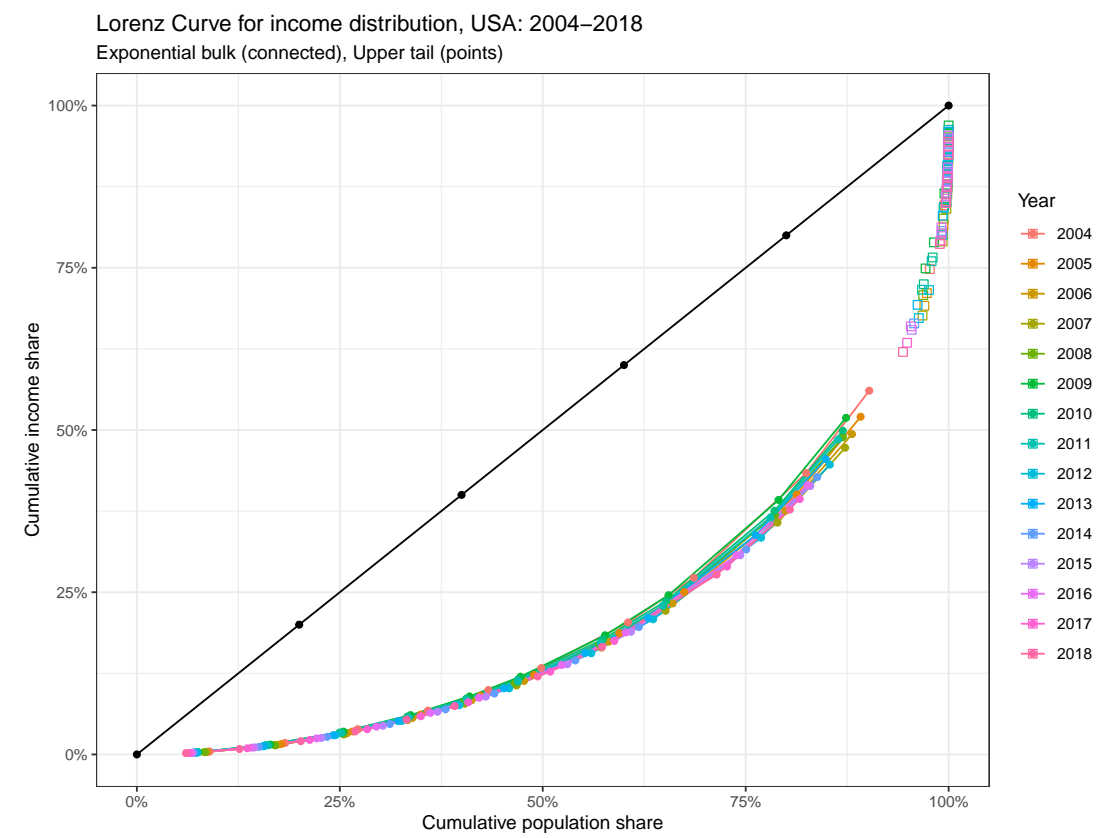

Figure 4: Lorenz curve partitioned by class 2004-2018

The classification of the vast majority in the lower class also has important implications from a political economy perspective. It is well documented that US labor productivity has outgrown typical wages in the post-1980s neoliberal period (Bivens et al., 2014). The gap between productivity and wages was a central explanation for surplus value (accruing to capitalists), according to classical economists like Adam Smith and Karl Marx. In the classical framework, workers' wages are socially determined and gravitate around subsistence, with labor force participation accomodating capital accumulation. Real wages were therefore considered to be fixed (Michl, 2016a; Foley et al., 2019). Obviously, for the vast 
majority in a welfare state, this is not true anymore. However, my data shows that the parameter $T$ (mean incomes for the lower class) has grown at the same rate as inflation over 2004-2018 - around 1.3 times (Figure 5). The interpretation is that lower class incomes are in fact constant in real terms over this period, consistent with classical models.

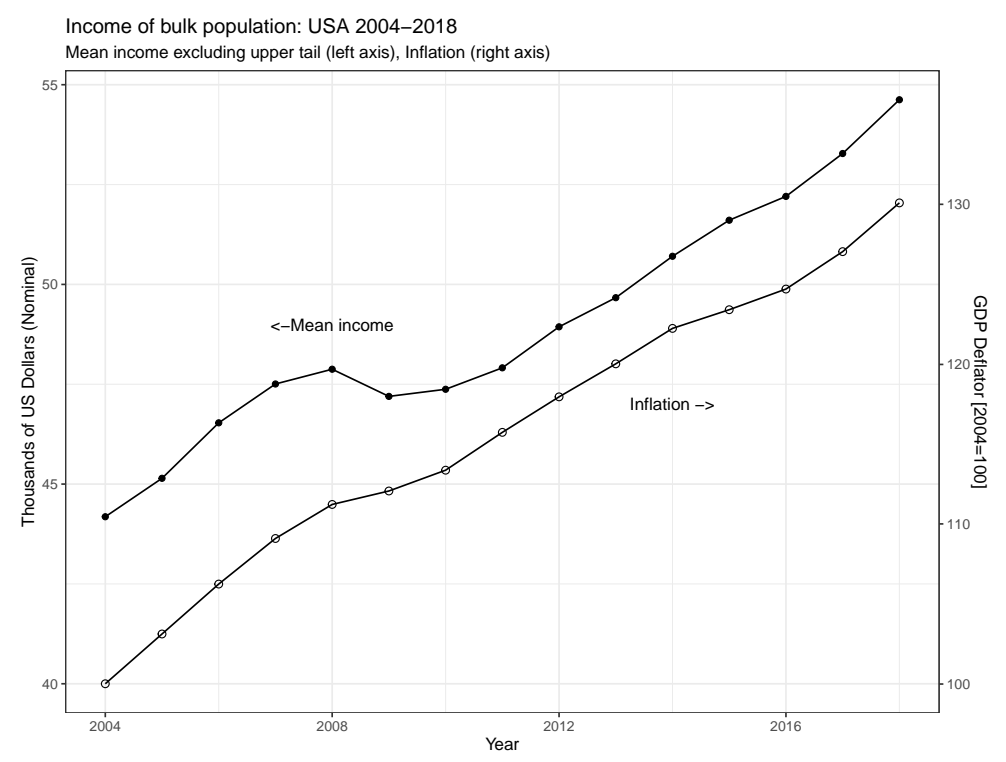

Figure 5: Mean incomes (T) over 2004-2018. Inflation on the secondary axis

\subsection{Capitalists, the working rich or homoploutia in the upper class?}

While the lower class shows analogy to workers in the classical model, it is unclear whether the upper class can be interpreted as a pure capitalist class. One strand of the income distribution literature proposes that the empirical finding of class partitions reflects the functional distribution of income between workers and 
capitalists - the lower (exponential) class represents workers while the upper class is essentially the capitalist class (Shaikh, 2017). Each distribution function can be derived as a stationary solution to distinct income processes. Nirei and Souma (2007) use stochastic models with multiplicative shocks to derive a power-law for capital incomes while Shaikh (2020) uses a drift-diffusion framework to constructively approximate a log-linear form for wages (exponential or lognormal) and a $\log -\log$ (power-law) probability fit for capital incomes.

The problem with this interpretation is that it does not explicitly test the shape of the distribution for different income sources. For example, wages, according to this reasoning, should be distributed exponentially. But, in fact, the rich in the modern society are not only capitalists but also well compensated professionals. And, when we consider income inequality in the bottom 99 percent, wage-skill dispersions play an important role (Autor, 2014). Nearly half the top decile of the US income distribution is rich in both labor and capital income - a phenomena referred to as "homoploutia" in Milanovic (2019). That is, through inheritance or through saving ${ }^{8}$ from high salaries, there is an overlap between the labor income rich and capital income rich at the top of the income distribution. This is especially prevalent in Western Europe and North American societies (Ranaldi and

\footnotetext{
${ }^{8}$ One possible explanation is historical. Piketty et al. (2018) showed that US income inequality was driven by labor income in the last few decades of the twentieth century, and by capital income subsequently. High salaries are considered labor income, and since labor income is earned, it is difficult to apply high tax rates. This leaves a high disposable income for acquisition of financial assets and generation of future capital incomes and inheritances to the next generation. As a result, one can observe the same individual earning a high salary, but also drawing significant capital income.
} 
Milanović, 2022), distinguishing modern day liberal-meritocratic capitalism from the classical variant of capitalism where being a capitalist and being rich meant the same thing.

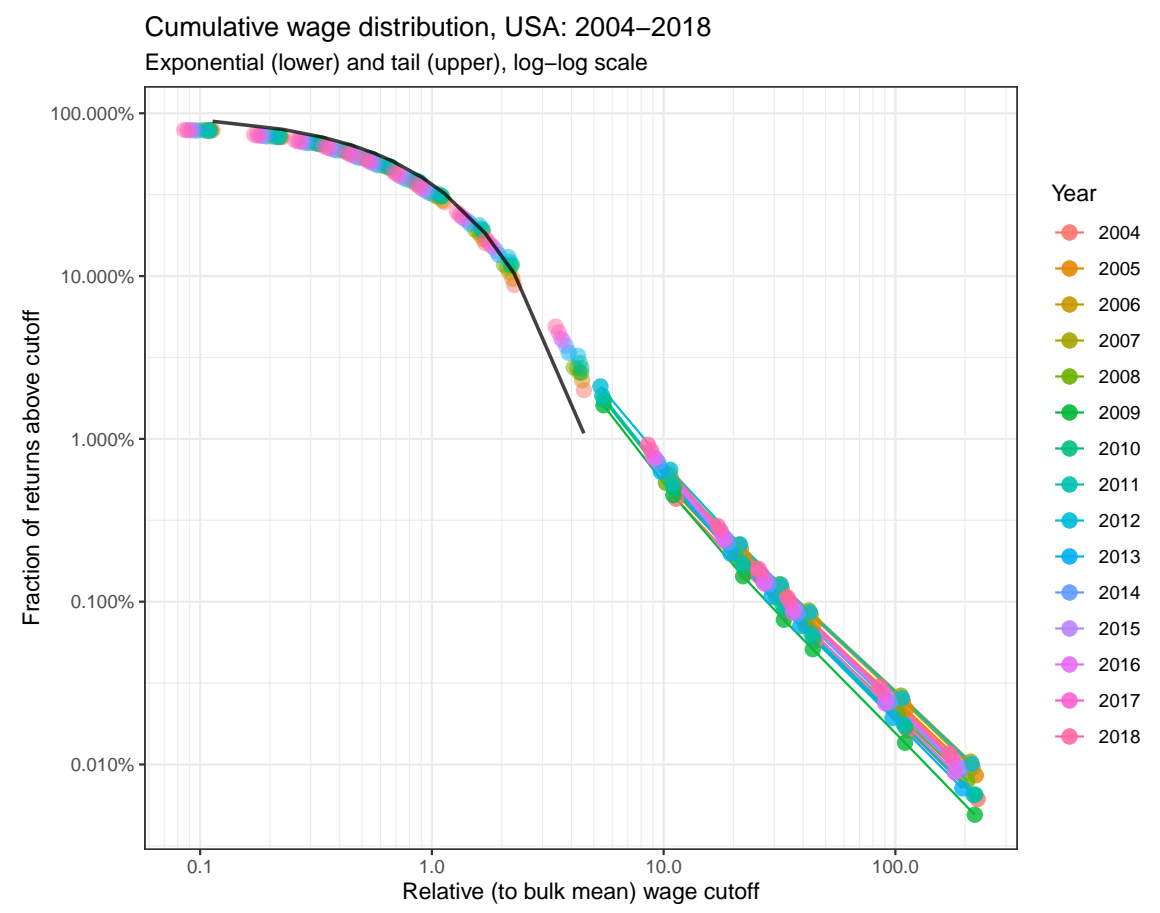

Figure 6: Two-class structure of wage and salary distribution on log-log scale

To test for homoploutia, I construct cumulative probabilities for labor incomes alone. In theory, if the classical model applies, then wages should only follow an exponential distribution (the lower class fit). The IRS provides tabulations of wages and salaries, organized in the same format as AGI. Using these data, I constructed the distribution in Figure 6 using the mean parameter $T$ and exponential line from AGI for comparison. Despite a very slight divergence, the data collapse in a hump shape again for the vast majority of wage earners. However, the discon- 
tinuity resurfaces for high wages and salaries, with the power law shape applying to the top 5-6 percent of the labor income distribution and extending to $100 \mathrm{~T}$ for the top 0.01 percent. The existence of a power law in labor income puts those rich in labor income in the upper class of the overall income distribution, besides pure capitalists.

To be sure, homoploutia, is a complementary explanation for the two-class structure of the income distribution in the US. Part of the top wage-earning class comprises athletes, actors and highly specialized professionals in the medical or legal profession. It is well known that the latter do earn significantly higher salaries than the typical American. For instance, a surgeon who earns over $\$ 500 \mathrm{~K}$ has more than ten times the mean income of the population. Still, for a power law at the top, the frequency of superstars should be less rare than reality; hence, star athletes are one in a million rather than one in thousand. The more parsimonious explanation is the distribution of top compensation and scaling due to firm size (Gabaix, 2016; Geerolf, 2017). One of the features of neoliberal capitalism is the entrenchment of supervisory classes within the workplace - supervisors, managers, executives, "supermanagers" and CEOs. Compensation structures for this class can manipulate legal jargon to lower tax burdens on the corporation and appear as wages on payrolls, even though in fact they may well represent distribution away from workers (Michl, 2016b).

\section{Evolution of aggregate inequality}

Finally, I turn to the determinants of income inequality over the period 20042018. To an extent, I have already answered this question because I showed that 
the lower class is in equilibrium inequality. Therefore, fluctuations to the overall income distribution emanate from inequality within the upper class, as well as the relationship between the parameters of the power-law and the normalizing variable $(T)$ derived from the lower class. The former is a within-class effect and the latter a between-class effect. Because income distribution has a thick upper tail, large shocks to the richest ${ }^{9}$ can move top income shares. Quantitatively, my analysis suggests that the between-class effect dominates as an explanation of increasing income inequality in the US.

To measure income inequality, I computed Gini coefficients for the entire population. Additionally, I also estimated Ginis for the lower and upper class. Because the two groups are ranked, and thus non-overlapping (the richest person in the lower class is poorer than everyone in the upper class), the population Gini can be fully decomposed ${ }^{10}$ into a between class and within class component, i.e. $G_{\text {total }}=G_{\text {between }}+G_{\text {within }}$ (the residual term ${ }^{11}$ is zero). As per convention, the within component is given by $G_{\text {within }}=\sum_{i} \phi_{i} G_{i}$ where $G_{i}$ is the Gini coefficient for class $i$ and $\phi_{i}$ is the product of population and income shares for class $i$.

\footnotetext{
${ }^{9}$ See, for example, Mohun (2016) for a comparison of top income shares and the fatness of the upper tail in the long run

${ }^{10}$ Schneider and Tavani (2016) also implement a decomposition of US incomes into upper and lower classes to estimate the impact of inequality within the rich and rest on aggregate inequality. Their methodology is based on the Jantzen and Volpert (2012) decomposition with a bridging term to approximate full decomposition of the aggregate gini coefficient.

${ }^{11}$ Given subgroups in a population, the Gini coefficient is decomposed as: $G=G_{\text {between }}+$ $\sum_{i} \phi_{i} G_{i}+R$ where $\mathrm{R}$ is the residual, $G_{i}$ is the Gini for subgroup $i$ and $G_{b e t w e e n}$ is the Gini obtained by replacing the income of everyone by their respective mean group incomes. See Yitzhaki and Schechtman (2013)
} 

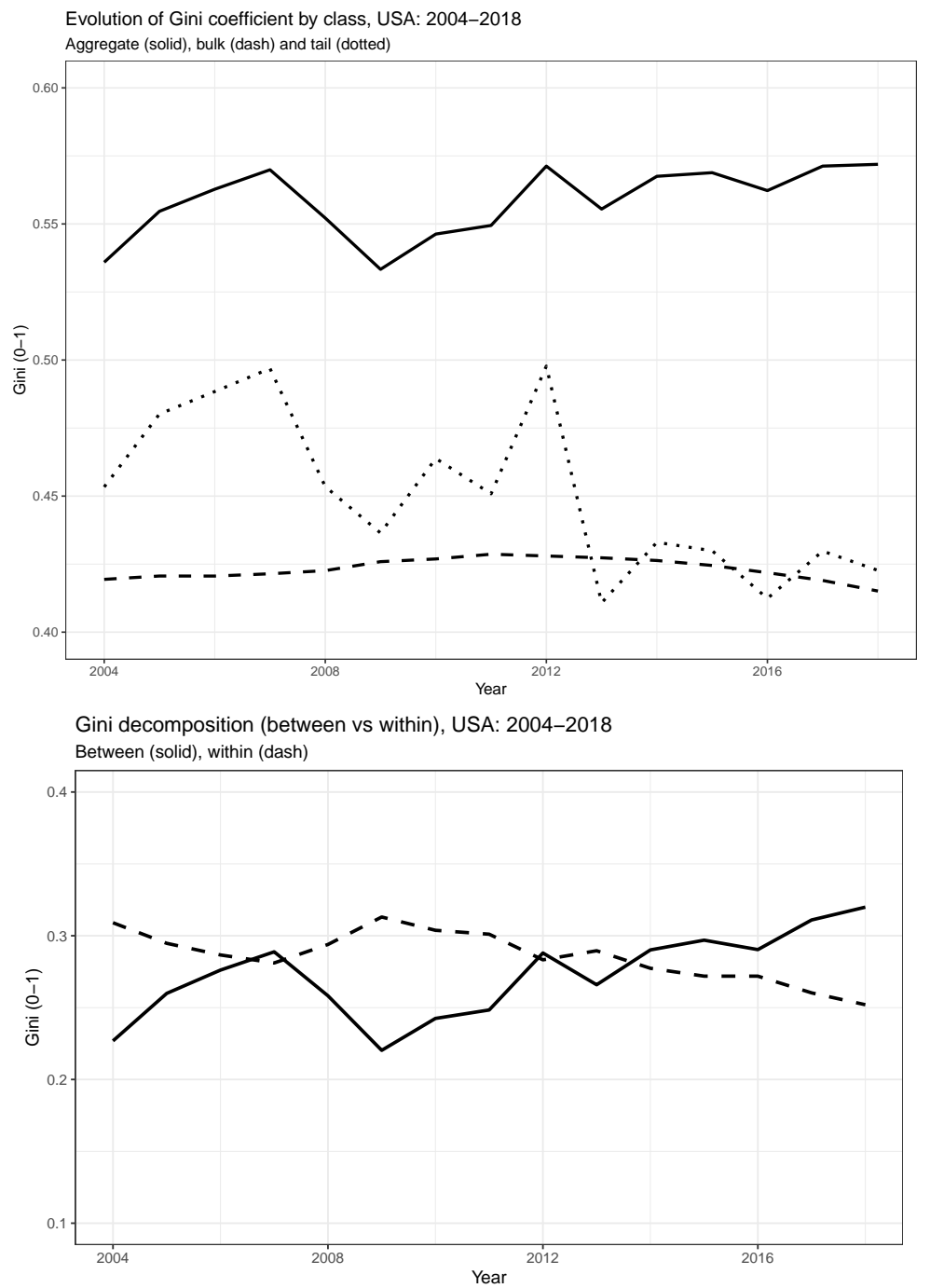

Figure 7: Gini coefficient by class (upper panel) and decomposition (lower panel) 2004-2018

The upper panel in Figure 7 shows the evolution of Ginis for the population, as well as the lower and upper class respectively. Mainly, since 2008, income inequality has increased while inequality within each class has declined. The 
population Gini picks up fluctuations in the upper class but the latter has declined and converged to the Gini for the lower class. Inequality within the lower class has been static over time, consistent with the stability of the exponential distribution discussed earlier. The lower panel shows decompositions over 2004-2018 and corroborates the waning influence of within-class inequality. $G_{\text {within }}$ was the dominant contributor to $G$ around 2004, but roles were reversed by 2018 as $G_{\text {within }}$ reduced while $G_{\text {between }}$ maintained an upward trajectory. In fact, the shape of the population Gini mirrors the between-class Gini (the rise in the latter is sharper).

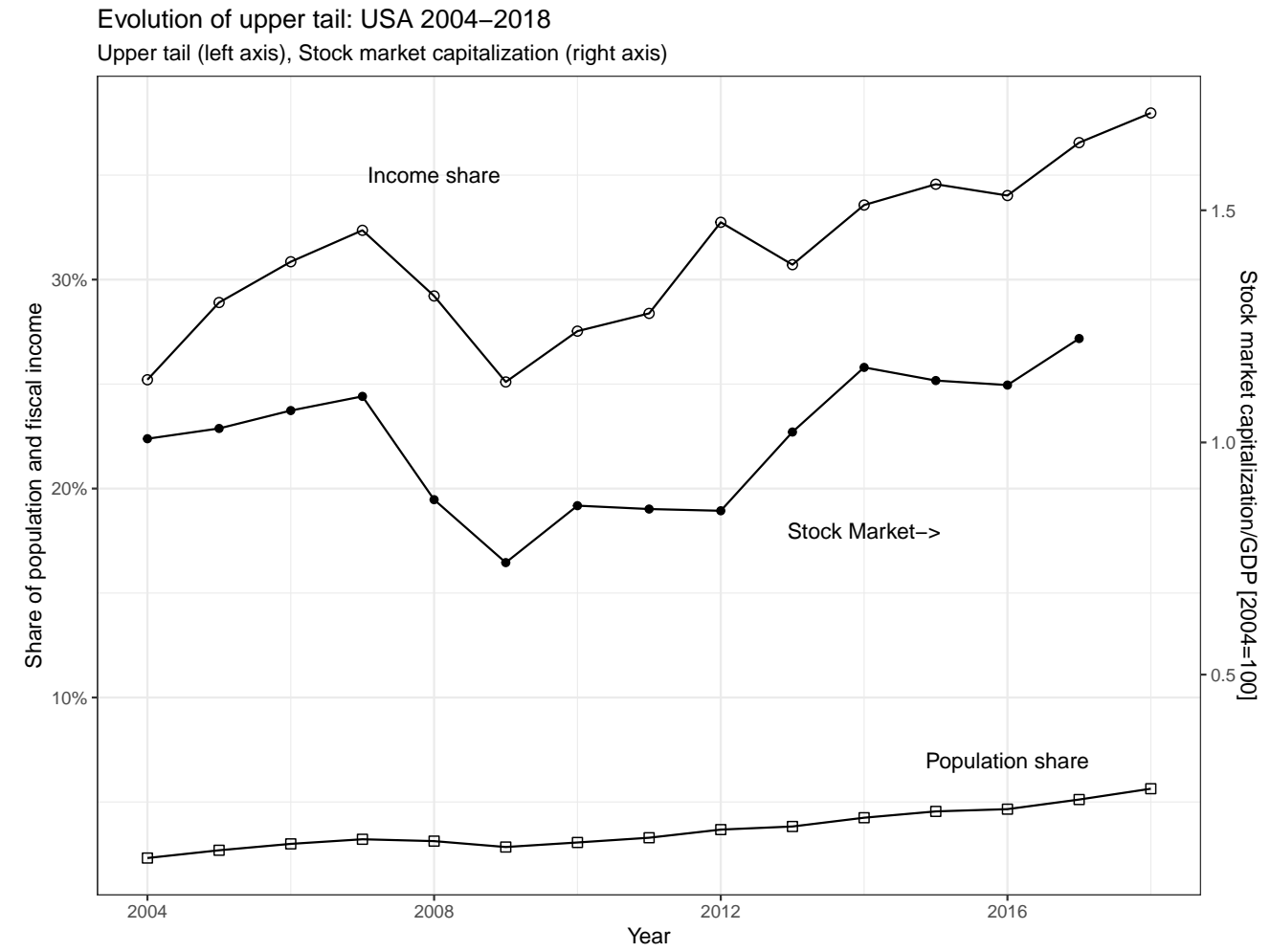

Figure 8: Income and population shares of the upper class. Stock market capitalization on secondary axis 
The rise of income inequality and the between-class effect becomes clearer looking at income and population shares over time. As Figure 8 shows, the fraction of income held by the upper class is very large relative to their share in the population. Capital market fluctuations - measured here using the ratio of stock market capitalization to Gross Domestic Product (GDP) - hold significant sway on fluctuations of upper class income shares. This is mainly due to the impact of windfall gains, or market crashes, on the fatness of the upper tail of income distribution. However, most salient is the secular rise in the fraction of population in the tail. Between 2004 and 2018, this fraction doubled from 3 to 6 percent. The effect of this class expansion ${ }^{12}$ on aggregate income inequality is disequalizing. In so far as the two classes are distinct, have no overlap and the upper class represents the rich, an encroachment from the top increases the upper class income share. Secondly, the between component of the Gini assigns to each individual the mean income of their subgroup. Thus, it allocates to a larger share of the population, already ranked at the top end of the overall income distribution, incomes that are an order of magnitude larger (the ratio of mean upper and lower class income is around 8-10).

\section{Concluding remarks}

Using the econophysics model, I attempted to produce generalizable results which harmonizes, in a simple way, different strands of the income inequality literature:

\footnotetext{
${ }^{12}$ To be sure, a similar encroachment from below (the lower class) would be equalizing because the income share of the lower class would increase by appropriating more population at the upper end of the overall income distribution
} 
the divergence of top income shares (Piketty et al., 2018), rising earnings (labor income) inequality within the bottom 99 percent (Autor, 2014) and the more heterodox class based explanation (Foley et al., 2019). What sets the current variant of capitalism apart from the past is that the rich comprise capitalists, and those who are rich in labor income as well - earning inequality is also important at the top. However, the essential feature of capitalism, regardless of variant, is its tendency to produce rising income inequality and class based divergence (despite what appear as blurred class lines) (Milanovic, 2019). This chapter has shown that there is a well defined two-class pattern to US incomes: the rich and the rest. And, while the rich are well paid workers, as well as traditional capitalists, the class based aspect of incomes is the main driver of inequality.

\section{References}

Atkinson, A. B. And T. PiketTy (2010): Top incomes: A global perspective, Oxford University Press.

Autor, D. H. (2014): "Skills, education, and the rise of earnings inequality among the "other 99 percent"," Science, 344, 843-851.

Bivens, J., E. Gould, E. Mishel, And H. Shierholz (2014): "Raising America's pay," Economic Policy Institute Briefing Paper, 378.

DrĂGulescu, A. AND V. M. YAKOVEnKo (2001): "Exponential and powerlaw probability distributions of wealth and income in the United Kingdom and the United States," Physica A: Statistical Mechanics and its Applications, 299, 213-221. 
Foley, D. K., T. R. Michl, AND D. TAVANi (2019): Growth and Distribution, Harvard University Press.

GABAix, X. (2016): "Power laws in economics: An introduction," Journal of Economic Perspectives, 30, 185-206.

Geerolf, F. (2017): “A Theory of Pareto Distributions,” Working Paper.

JANTZEN, R. T. AND K. VOLPERT (2012): "On the mathematics of income inequality: Splitting the gini index in two," The American Mathematical Monthly, $119,824-837$.

Michl, T. R. (2016a): "Capitalists, Workers and Thomas Piketty's Capital in the 21st Century," Review of Political Economy, 28, 205-219.

_ (2016b): "Rentier Consumption and Neoliberal Capitalism," International Journal of Political Economy, 45, 182-199.

Milanovic, B. (2019): Capitalism, alone, Harvard University Press.

Mohun, S. (2016): "Class structure and the US personal income distribution, 1918-2012," Metroeconomica, 67, 334-363.

NiReI, M. AND W. Souma (2007): “A two factor model of income distribution dynamics," Review of Income and Wealth, 53, 440-459.

Pareto, V. (1896): Cours d'économie politique, vol. 1, Librairie Droz.

Piketty, T. And E. SAez (2003): "Income inequality in the United States, 1913-1998," The Quarterly journal of economics, 118, 1-41. 
Piketty, T., E. SAeZ, And G. ZuCMAn (2018): "Distributional national accounts: methods and estimates for the United States," The Quarterly Journal of Economics, 133, 553-609.

Ranaldi, M. AND B. Milanović (2022): “Capitalist systems and income inequality," Journal of Comparative Economics, 50, 20-32.

SCHNEIDER, M. P. (2015): "Revisiting the thermal and superthermal two-class distribution of incomes," The European Physical Journal B, 88, 1-10.

SChneider, M. P. AND D. TAVAni (2016): "A tale of two Ginis in the US, 1921-2012," International Review of Applied Economics, 30, 677-692.

SHAIKH, A. (2017): "Income distribution, econophysics and piketty," Review of Political Economy, 29, 18-29.

- (2020): “The econ in econophysics," The European Physical Journal Special Topics, 229, 1675-1684.

Silva, A. C. And V. M. Yakovenko (2004): "Temporal evolution of the "thermal" and "superthermal" income classes in the USA during 1983-2001," EPL (Europhysics Letters), 69, 304.

Tao, Y., X. Wu, T. Zhou, W. Yan, Y. Huang, H. Yu, B. Mondal, and V. M. YAKOVENKO (2019): "Exponential structure of income inequality: evidence from 67 countries," Journal of Economic Interaction and Coordination, $14,345-376$.

Yitzhaki, S. And E. Schechtman (2013): The Gini methodology: A primer on a statistical methodology, Springer. 